\title{
Design Proportional Integral Controller Using Facts Device for Voltage Compensation
}

\author{
Saurabh Patel ${ }^{1}$, Chandra Kant Sahu ${ }^{2}$ \\ ${ }^{1,2}$ Department of Electrical and Electronic Engineering, Lovely Profession University, Jalandhar, Punjab, India
}

\begin{abstract}
In this paper a new methodology and approach is used to design a controller which can control the voltage sag and system abnormalities at fault condition. For approaching this we use FACTS devices and proportional integral (PI) controller. Fact devices enhance the system voltages problem, harmonics and stabilities. Different types of FACTS devices are available in power system. The DSTATCOM is more suitable in voltage sag problem control. It is a shunt connected FACTS device. In MATLAB model it is combined with the proportional integral (PI) control which is cheaper and it's functioning is very easy. In this controller we have us ed 2 bus transmission power system using MATLAB/SIMULINK software.
\end{abstract}

Keywords: PWM, D-STATCOM, PI, FACTs, VSC

\section{Introduction}

Present time the power system transmission line faces various problem due to the changes in the load variation, occurrence of certain fault and increase in demand. The compensation technique can be used to overcome this situation. The FACTS (flexible ac transmission System) technology is a promising approach to assure power system problem. This approaching method is based on the introduction of power electronic devices in the traditional ac power system. The insertion of power electronic devices enhances the capability, controllability and transfer limit of the power system.

At a present time, power quality, voltage regulation dynamic fluctuation these are most furious problem occurs in the power system. The voltage problem is generally occurring due to the occurrence of fault. The severity of voltage problem depends on the type of fault. line to line, line -line line, line-ground, line-line-line-ground (L-L-L-G). the lineline-line-ground type fault is more dangerous and makes system voltage in worst condition than other type of fault in these paper we are trying to control the basic parameter and the voltage sag and voltage regulation of power system with the help of proportional integral (PI) and the distribution static synchronous compensator (DSTATCOM). There is further more technique is used for installation and control of FACTS devices. There is a lot of technique used for control of facts devices like PI controller, fuzzy logic, neuro fuzzy. But the PI controller is a very prominent method for controlling the FACTS devices. The application and design processes of controller is described in the further chapter.

\section{D-STATCOM Operation}

D-STATACOM is a shunt type voltage compensator that mean there should be coupling transformer connected in between the distribution system and the D-STATCOM for isolating the DSTATCOM form distribution system. the device should be install very close to load so that it can maximize its compensation capability. D-STATCOM is very useful in case of where the AC system is weak in magnitude. The modelled diagram and component of D-STSTCOM is described below:
This is made with the help of voltage source convertor (VSC) and RC circuit. it is further connected with the 3 phase 3 winding transformer. The gating signal is given to the voltage source convertor with the help of PI controllers pulse generator. The VSC is connected RC circuit which acts as a filter.

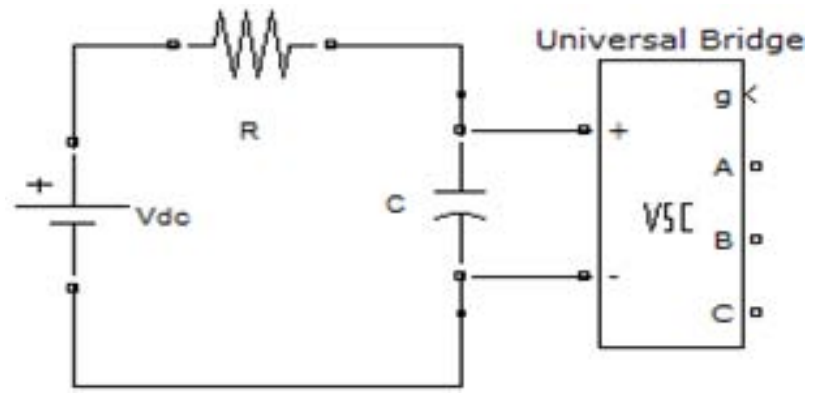

Figure 2.1: DSTATCOM MATLAB model

\section{PI Controller}

it is used to provide the control logic by controlling the gating signal of voltage source convertor. the value of input is taken from the VI measurement block. That is further processed, compare and generate the pulses to control the DSTATCOM.

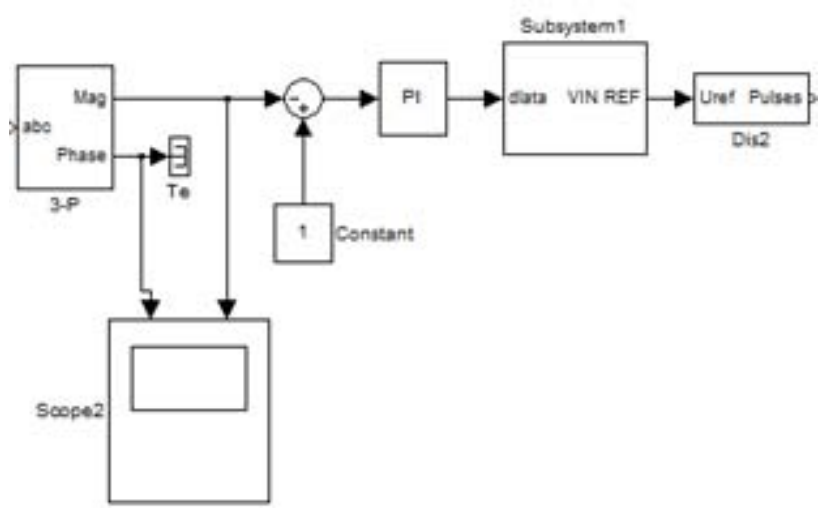

Figure 3.1: PI Simulink model 


\section{International Journal of Science and Research (IJSR) \\ ISSN (Online): 2319-7064}

Index Copernicus Value (2013): 6.14 | Impact Factor (2014): 5.611

\section{MATLAB Simulation Model}

The proposed model is tested on 2 bus model with source at both end. the source system is configured with $25 \mathrm{kv}, 50 \mathrm{~Hz}$ the transformer is of $250 \mathrm{MVA}$. we have used converter having 6 pulse with 3 arm and sampling time 5 micro second. The simulation is run for 1 second and fault duration is given between $0.2 \mathrm{~s}$ to $0.4 \mathrm{~s}$.the Simulink model is shown below:

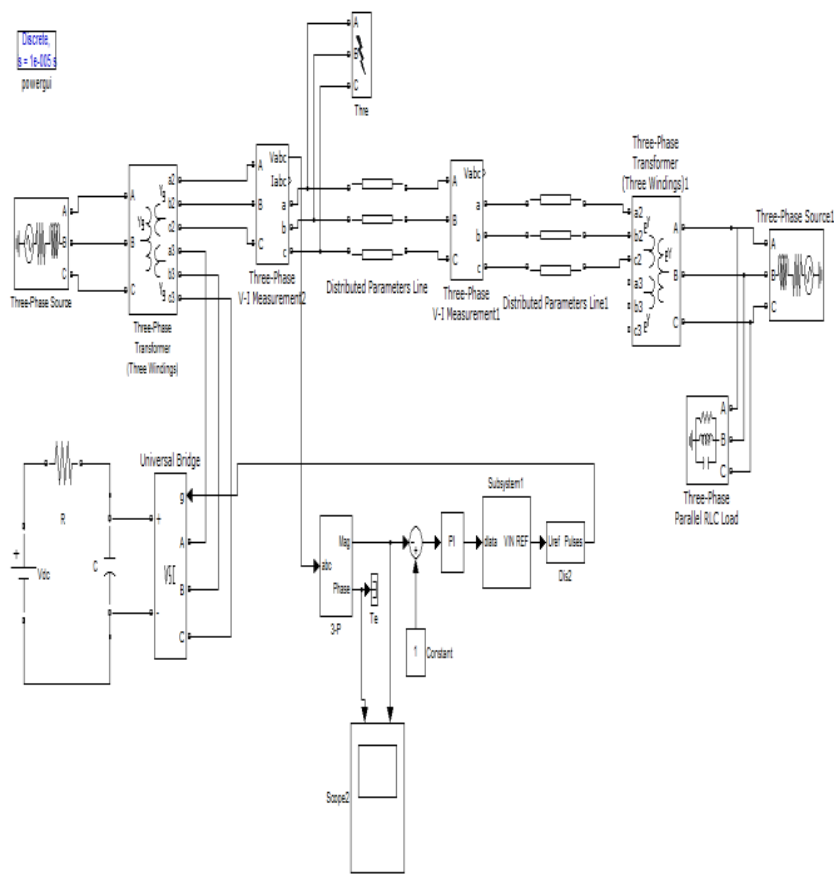

Figure 4.1: Shows the complete model of PI controlled DSTACOM

After simulating the graph of output power is shown that is represented below. The magnitude of power, phase is shown in all condition like before fault with fault and without fault.

\subsection{Without fault ideal condition:}

This case considers that there is no any fault in any phase of line. The phase graph is downward and it stabilizing itself at value of -30.the the magnitude graph is showing its value around 8.7. The simulation graph is shown below.

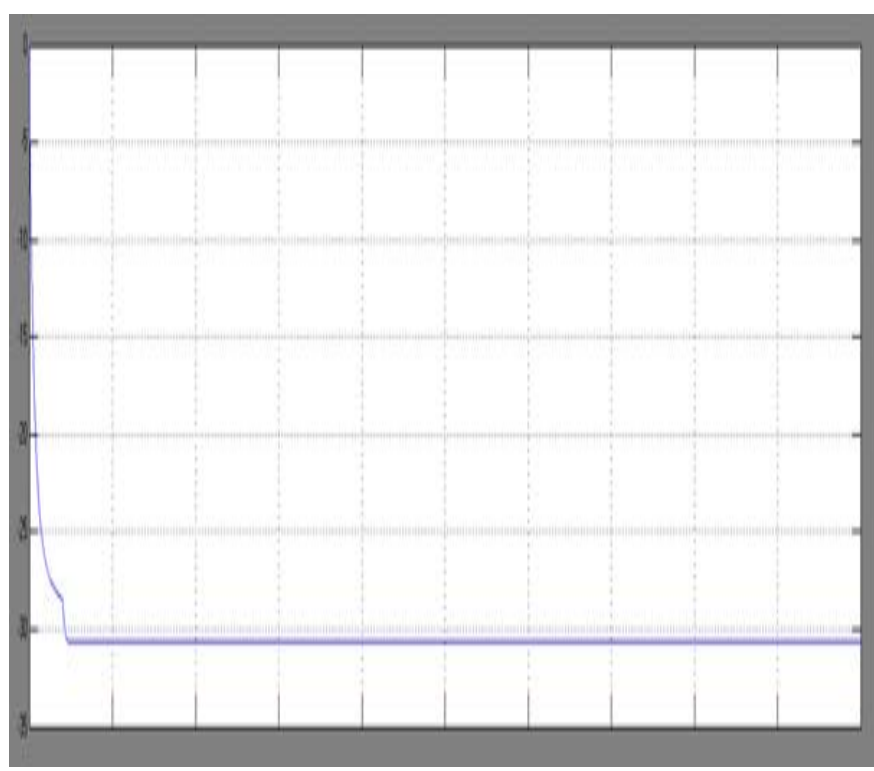

Figure 4.2: Show phase graph of voltage without fault in system

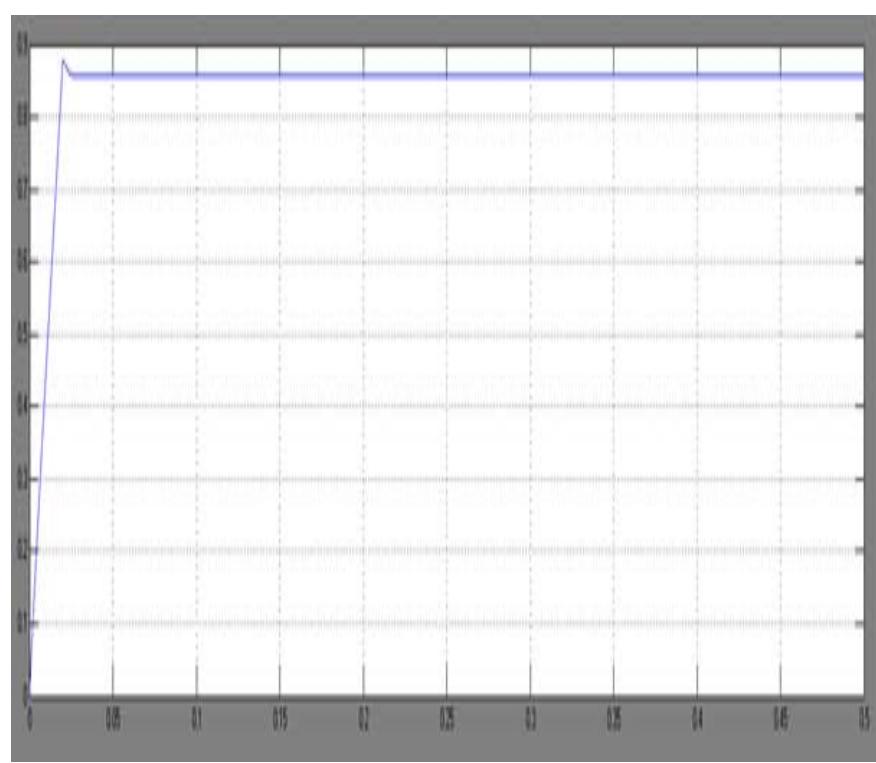

Figure 4.3: Magnitude graph of voltage without fault in system

\subsection{Fault Condition}

In this condition the fault is introduces in the system in all phase of line with respect to the ground. There are many other condition of fault that can simulate and analysis the same way. As the fault condition changes like LLLG to LLG the drop in magnitude and phase is less compare to LLLG fault condition. during the fault period 0.2 to 0.4 the phase graph shows more downward slope stabilizing at value -60 during the fault duration. while magnitude is at 0.5 p.u. during time period of fault. 


\section{International Journal of Science and Research (IJSR) \\ ISSN (Online): 2319-7064}

Index Copernicus Value (2013): 6.14 | Impact Factor (2014): 5.611

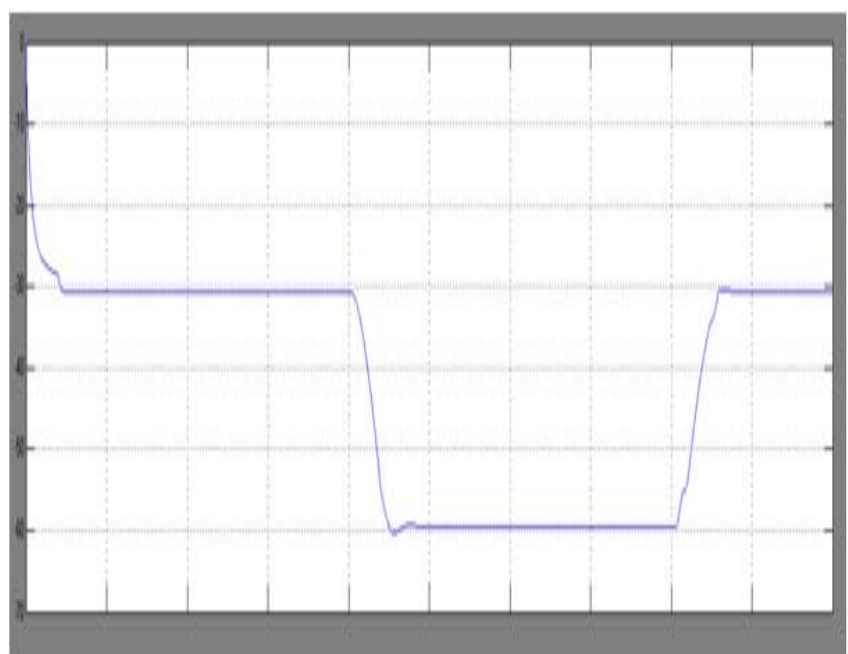

Figure 4.4: phasegraph of voltage with fault in system

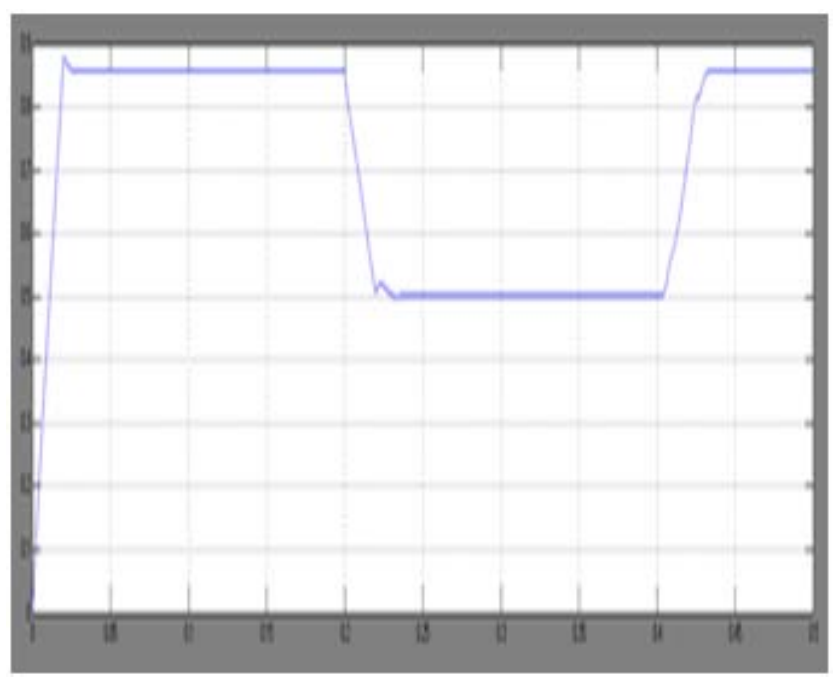

Figure 4.5: magnitude graph of voltage with fault in system

\subsection{Fault Condition with Compensator}

Using compensator, we can see that fault is control led and the losses is reduced to acceptable level.as we see in figure the phase fault value is reduces from value -60 to -18 and the same the magnitude value is reduced to 8.9 from $0.5 \mathrm{pu}$.

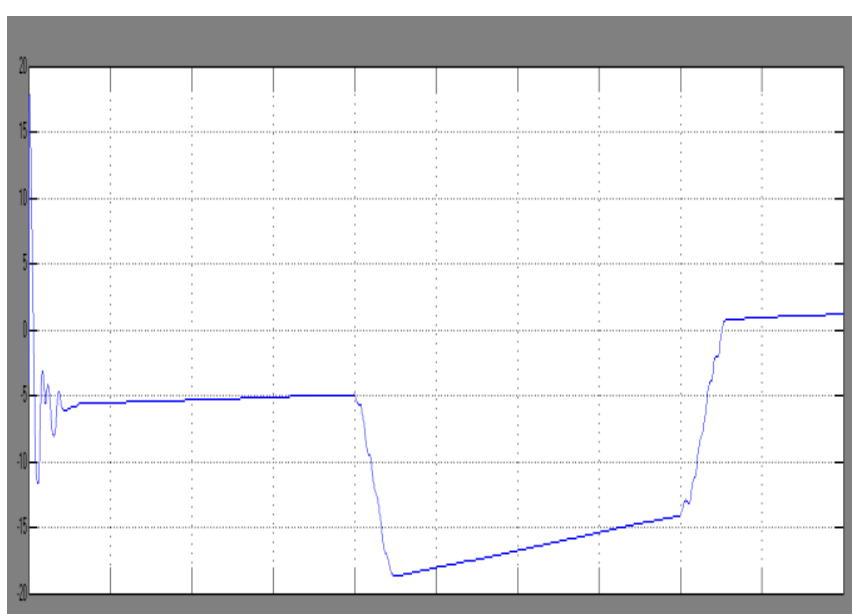

Figure 4.6: Phase graph of voltage in compensated system

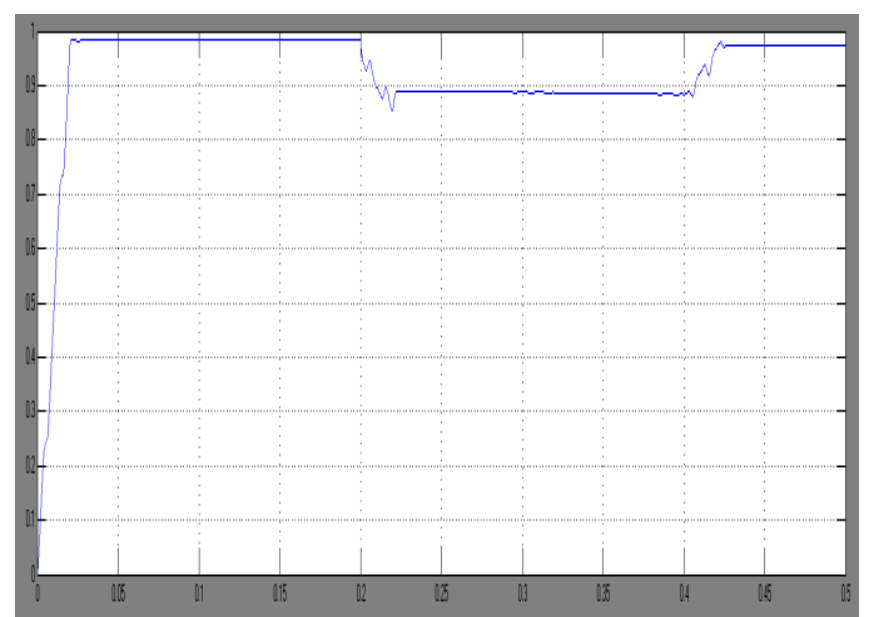

Figure 4.7: Magnitude graph of voltage in compensated system

\section{Result}

From above simulation it is clear that PI based DSTATCOM is working sufficiently to control the power system problem. The above simulation and compression is done for the time interval 0.2 to 0.4 second.

\begin{tabular}{|c|c|c|}
\hline Condition & Phase $(\mathrm{Pu})$ & Magnitude( $\mathrm{Pu})$ \\
\hline Ideal & -31 & 8.7 \\
\hline Fault & -60 & 0.5 \\
\hline Compensated & -18 & 8.9 \\
\hline
\end{tabular}

\section{Conclusion}

In this thesis report designing of controller id with the help of PI controller. here we investigated the 3-phase fault under different condition. We have analysis the different fault condition and different degree of compensation. We used PI based D-STATCOM compensator to control voltage unbalance and sag condition in power system. The important thing is to choose right value and transmission fundamental component value. The difference between ${ }_{\text {ref }}$ and $V_{\text {mean }}$ and also the difference of $I_{\text {ref }}$ and $I_{\text {mean }}$ and their derivatives is provided to the controller as input and the $\mathrm{K}_{\mathrm{p}}$ and $\mathrm{Ki}$ is taken out as output parameter of controller(PI). The proposed model is simulated and analyzed in the MATLAB/SIMULINK. The simulation indicates that the DSTATCOM based PI controller in 3-phase gives good performance compare to other FACTS devices.

\section{References}

[1] R. Mohan Mathur, Rajiv k. varma, "thyristor based FACTS controller for electrical transmission system", IEEE press series on power engineering, John Wiley \& son's publishers, 2002, pp: 413-457.

[2] Ghosh and G.ledWich; "power quality enhancement using custom power devices" kluweracaremic publisher, boston, 2002.

[3] H. Akagi, Y. Kanazawa, and A. Nabae, "Instantaneous reactive power compensators comprising switching devices without energy storage components," IEEE Trans. on Ind. Appl. Vol. 20, no. 3, 625-630, 1984.

[4] F. Z. Peng and J. S. Lai, "Generalized instantaneous reactive power theory for three-phase power systems," 


\section{International Journal of Science and Research (IJSR) \\ ISSN (Online): 2319-7064}

Index Copernicus Value (2013): 6.14 | Impact Factor (2014): 5.611

IEEE Trans. on Instrumentation and Measurement. Vol. 45, no. 1, 293-297, 1996.

[5] S. Tzafestas and N. P. Papanikolopoulos, "Incremental fuzzy expert PID control," IEEE Transactions on Industrial Electronics, Vol. 37, pp. 365-371, 1990.

[6] P. Venkata Kishore et. al. "Voltage sag mitigation in eight bus system using D-STATCOM for power quality improvement" International Journal of Engineering Science and Technology Vol. 2(4), 2010, pp.529-537.

[7] Mahesh K. Mishra, Member, IEEE, and K. Karthikeyan "A Fast-Acting DC-Link Voltage Controller for Three Phase DSTATCOM to Compensate AC and DC Loads" IEEE Transactions On Power Delivery, VOL. 24, NO. 4, OCTOBER 2009, pp. 2291-2295

[8] Masand, D., Jain, S., Agnihotri, G., "Control Strategies for Distribution Static Compensator for Power Quality Improvement", IETE Journal of Research, 54(6): 421428 (2008).

[9] Miller, T.J.E., "Reactive Power Control in Electric Systems", Toronto, Ontario, Canada, Wiley, (1982). [3] Mathur, R.M., "Static Compensators for Reactive Power Control", Contexts Publications, Winnipeg, Canada, (1984).

\section{Author Profile}

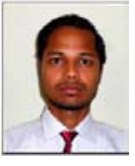

Saurabh Patel is currently pursuing B. Tech.-M. Tech. (dual degree) in Electrical and Electronics Engineering in Lovely Professional University, Phagwara, Punjab. And currently working on research for PI controller using advanced fuzzy techniques.

Chandra Kant Sahu is currently pursuing B. Tech.-M. Tech. (dual degree) in Electrical and Electronics Engineering in Lovely Professional University, Phagwara, Punjab. And currentlyworking on research for improvement of solar panel conversion efficiency. 